\title{
Arabic Language Teachers' Engagement with Published Educational Research in Kuwait's Secondary Schools
}

\author{
Hamed A. Alhumidi ${ }^{1} \&$ Sani Yantandu $\mathrm{Uba}^{2}$ \\ ${ }^{1}$ College of Basic Education, PAAET, State of Kuwait \\ ${ }^{2}$ University of Leeds, UK \\ Correspondence: Sani Yantandu Uba, University of Leeds, UK
}

Received: January 23, 2017

Accepted: February 26, 2017

Online Published: March 1, 2017

doi:10.5430/ijhe.v6n2p20

URL: https://doi.org/10.5430/ijhe.v6n2p20

\begin{abstract}
This study investigates Arabic language teachers' engagement with published educational research in Kuwait's secondary schools. The study employs 170 participants across six educational regions in the country by using a quota sampling strategy. It used a questionnaire in eliciting their engagement with published educational research. The data were analysed by using simple percentage to describe the scenarios of their engagement with the published educational research. The results show that there is a lack of encouragement and support by their institutions in relation to teachers' engagement with published educational research. It also indicates that the findings of the study do not relate to their practical teaching.

This study recommends that there should be raising of awareness of the teachers on the importance of published educational research. Researchers should be cognizant of the needs of teachers and important roles that teachers could play in the implementation of the findings of the research. It also suggests the development of teachers' capacity-building such as teachers' research literacy. This could assist teachers to develop their reading and writing, as well as engaging with published educational research. Again, the study advocates the development of organisational cultures which could support teachers' engagement with research. This might help in developing teachers' professional development in relation to their engagement with published educational research.
\end{abstract}

Keywords: Arabic language teachers, Published educational research, Kuwait, Evidence-based profession, Pedagogical knowledge, Research-based knowledge

\section{Introduction}

Several studies have been conducted on the English language teachers' use of educational research to improving their practice. For example, Borg (2010) investigates English language teachers' conceptions of research. Vanderlinde and Van Braak (2010) examine the relationship between educational research and practice in Dutch-speaking region in Belgium. Anwaruddin (2016) studies 12 in-service TESOL teachers' responses from USA and Canada regarding their engagement with educational research. Hemsley-Brown and Sharp (2003) also study English language teachers' use of educational research to improve their professional development in European countries. Again, Anwaruddin and Pervin (2015) focus their study on the English language teachers' engagement with research in Bangladesh. Tavakoli and Howard (2012) dwell on the TESOL teachers' views on the relationship between research and practice in the UK. Cain (2015) investigates secondary school teachers' engagement with published research in North of England. However, there is a lack of published research on teachers' engagement with published educational research in Kuwait's secondary schools, particularly in Arabic language teachers; and many scholars have argued that socio-cultural context plays significant roles towards production and reception of knowledge. As a result of this, this study seeks to investigate Arabic language teachers' engagement with published educational research and its impact of their practical teaching in Kuwait's secondary schools.

\subsection{Literature Review}

Hargreaves (1996) has raised a considerable debate in which he has argued the teaching profession is unfavourably compared to that of medicine. Hargreaves premises his argument that in medicine professional decisions, such as treatment of a particular ailment, is 'based on the best available research evidence' (Hemsley-Brown and Sharp, 2003:449). The rationale is to ensure that patients have been receiving most appropriate and effective treatment with the greatest likelihood of success. However, teachers rarely utilise educational research regarding their decisions about what is best for their students (Hemsley-Brown and Sharp, 2003:449). Hargreaves (1996) argues further the 
teaching profession should become 'an evidence-based profession if educational researchers were made more accountable'. Hemsley-Brown and Sharp (2003:449) have argued further that 'this could be achieved through a coordinated approach to research', such research would focus on pedagogical implications. For Borg (2010: 410) 'teachers should be critical consumers of educational research, using it to inform their instructional decisions'.

However, many scholars have argued that there is a gap between educational research and practice in the field of education (Anwaruddin and Pervin, 2015, 2016; Hargreaves, Hemsley-Brown and Sharp, 2003; Ball, 2012; and Vanderlinde and Van Braak, 2010). According to Anwaruddin and Pervin (2015) the gap is divided into three. The first group is of the view that researchers fail to attend to the needs of educational practitioners. Again, they also blame the researchers for constructing research questions, as well as designing research methodology without due consultation with practitioners; and in many instances research findings are 'inaccessible' to the practitioners. The second group believes that teachers are not using research-based knowledge to improve their practice (Hargreaves, 1996). The third group blames the organisational culture of the school, which lacks organisational culture that might support the use of research knowledge, which could be the main obstacle for teachers to access and utilise research (Anwaruddin and Pervin, 2015: McIntyre, 2005; Broekkamp and Van Hout-Wolters, 2007).

Cain (2015) posits that there are a number of studies which raise several questions on whether published research evidence could inform educational practice. He argues further that these questions are classified into seven themes. The first theme is whether the medical model of research evidence-based practice could be applied on educational practice (Biesta, 2007; Hammersley, 1997; and Slavin, 2002). The second theme is whether the methods which are most often cited by enthusiasts are appropriate or sufficient to be used by educational practitioners (Slavin, 2002, 2008; Torgerson and Torgerson, 2001; and Morrison, 2001). The third theme is to do with what could motivate teachers to implement findings from educational research. Is it legislation or financial inducements? Or is it change of agents or opinion leaders are necessary or sufficient? (Cain, 2015; Hemsley-Brown and Sharp, 2003; Bolam, 1994; Nutley, Walter, \& Davies, 2003; and Wikeley, 1998). The fourth theme asks question that among the stakeholders of education 'who is best to support the implementation of research findings - researchers, teachers, school leaders or local authorities' (Cain, 2015:490; Hemsley-Brown and Sharp, 2003; and Nutley, et al., 2003). The fifth theme is concerned with the roles play by research producers, as well as users and intermediary organisations (Cain, 2015; Levin, 2013 and Sharples, 2013). The sixth theme is concerned with what kind of activities that can best lead to research-informed practice, such as CPD, action research or other interventions (Cain, 2015; and Nutley, et al., 2003). The final theme is concerned with whether the knowledge of the research findings could in principle, be implemented in practice (Cain, 2015; Biesta, 2007, 2010; and Hammersley, 1997).

Cain (2015) has again claimed that the last theme is the most fundamental importance among the themes on the basis that knowledge of the findings from published research if could not be in principle implemented in practice, the other themes are irrelevant. Many scholars have argued that the last theme, which is based on the research evidence use within the teaching profession has been very scanty (Nelson \& O'Beirne, 2014 and Levin, 2013). Levin (2013) states further that:

There are many works analyzing situations, decrying weaknesses or proposing actions, but not nearly as much careful evidence on how and why research evidence is actually used in practice ... The irony has been noted more than once that the debate over the use of research is itself not well informed by research. (Levin, 2013, p. 4).

This foregrounds the claim that there is a lack of substantial research on whether the knowledge of the research findings could in principle, be implemented in practice as I have noted above.

\subsubsection{The Gap between Research and Practice}

Vanderlinde and Van Braak (2010) have argued that many scholars have raised questions regarding the gap between educational published research and practice for many years. They argue further this gap has been well documented and has also given rise to lively debates among policy makers, researchers, as well as practitioners. They also claim this gap reflects two kinds of contrasting knowledge. On one hand, there is a research-based knowledge, which usually published in scientific journals. On the other hand, there is a pedagogical knowledge, which teachers use in the classroom for their day-to-day teaching (McIntyre, 2005). For Bates (2002) the tension usually arises between teachers and researchers on the premise that teachers ask for new solutions to operational problems, whereas the researchers seek new knowledge. 
Anwaruddin and Pervin (2015) assert that both researchers and practitioners have pondered on the issue of the research-practice gap in education that many have become sceptical about the usefulness of educational research. As Kennedy puts forward four hypotheses on this scepticism:

(a) The research itself is not sufficiently persuasive or authoritative; the quality of educational studies has not been high enough to provide compelling, unambiguous, or authoritative results to practitioners. (b) The research has not been relevant to practice. It has not been sufficiently practical, it has not addressed teachers' questions, nor has it adequately acknowledged their constraints. (c) Ideas from research have not been accessible to teachers. Findings have not been expressed in ways that are comprehensible to teachers. (d) The education system itself is intractable and unable to change, or it is conversely inherently unstable, overly susceptible to fads, and consequently unable to engage in systematic change. (1997, p. 4)

Anwaruddin and Pervin (2015) note further that these four hypotheses have been further explored by some researchers. For instance, in a study conducted by Hemsley-Brown and Sharp (2003) regarding teachers' use of published educational research for improving pedagogical practices corroborates Kennedy's four hypotheses. One of the findings indicates that 'very few teachers turned to research literature to expand professional knowledge, solve problems or to meet the requirements of their job. Teachers ... perceived it (research) to be irrelevant, unhelpful and too theoretical' (Hemsley-Brown and Sharp, 2003: 284). Ball (2012) also acknowledges this gap as she argues educational researchers should not only generate knowledge but should also 'promote the use of research to improve education and serve the public good' (p. 284).

Again, Anwaruddin and Pervin (2015) have argued educational stakeholders have been pondering the question of how teachers learn and develop as professionals. They argue further that Hargreaves and Fullan (1992) provide a three-approach which could address the question in relation to teacher development. The approaches include knowledge and skill development, ecological change, as well as self-understanding. The first approach is concerned with how 'teachers equipped with appropriate knowledge and skills are better able to provide their students with better opportunities to learn' (Anwaruddin and Pervin, 2015: 25). This approach is relevant to this research because our concern is how teachers prepare him/herself with appropriate skills and knowledge that he/she can develop both $\mathrm{him} / \mathrm{herself}$ and provide students with appropriate learning opportunities.

\subsubsection{Empirical Studies}

This study reviews some of the empirical studies. Borekkamp \& van Hout-Wolters (2007) investigated the gap between published educational research and practice. They employed 160 educational stakeholders in Amsterdam: 51 educational researchers, 32 policy-makers or managers, 20 trained teachers, 19 teachers, 12 students of educational science, 5 designers of teaching materials, as well as 2 teachers-in-training. They also included 19 participants who were outside of these categories. The findings of this study indicate that practitioners make little or no use of findings of published educational research on the basis that the findings of such research provide very few conclusive and practical results. Although this study has provided some insights on the gap between published educational research and practice. However, it has some limitations, for example, the participants involved many categories of stakeholders with the actual teachers of less than 50\% of the total participants. The researchers did not specify the areas of specialisation of the participants, although they indicated 19 out of them were journalists. Again, the context of the study is Amsterdam and we believe socio-cultural context plays significant roles in the construction of knowledge.

Borg (2009) examines the conception of research by English language teachers across 13 countries. He employed questionnaires and supplemented by follow-up interviews. He finds that teachers' conception of published educational research is aligned with conventional scientific notions of inquiry. The study also shows that teachers have moderate level of reading and doing research, which they attributed to the lack of time, knowledge, as well as access to material, which teachers believe as main factors that limited their ability to be engaged in research. Although, this study is a large scale which cuts across many countries across the world, its concerned is on English language teachers. Again, this study does not include Kuwait context and socio-cultural context varies in the construction of knowledge. Again, this study does not specify whether the teachers are from primary schools, secondary schools, high schools or universities.

As noted in section 1.1 above, Vanderlinde and Van Braak (2010) focus their study on the relationship between published educational research and practice in Flanders, the Dutch-speaking region of Belgium. They employed four homogenous group involving 12 participants from each group. The group of participants are: teachers, school leaders, 
researchers and intermediaries. They use a focus group interview with the participants. The results of the study suggest that there is a gap between published educational research and practice; and it is very complex, as well as differentiated phenomenon than commonly assumed. The study advocates establishing 'professional learning communities' or promoting a 'designed-based research' model. However, this study has some limitations, for example, it combined many stakeholders rather than teachers alone. The study is conducted in Belgium not in Kuwait context. Again, it did not specify the areas of specialisation of the teachers.

Anwaruddin and Pervin (2015) investigate English language teachers' engagement with research in Bangladesh context. They employed 40 teachers: 20 at primary schools and the other 20 at high schools. The study also used both questionnaire and in-depth interviews. The findings of this study indicate that there is a lack of teachers' engagement with published educational research regarding their professional development. They recommend the development of individual teachers' capacity-building such as teachers' research literacy. They also advocate development of organisational cultures which could support teachers' engagement with research. Although this study combined both questionnaire and in-depth interviews; however, it is concerned with English language teachers only and the context of the study is Bangladesh.

In another study, Anwaruddin (2016) also focuses his study on the responses of English language teachers to published educational research. Using a wiki-based discussion group, he employed 12 in-service teachers across many countries. The study integrated both a wiki-based board and interview as source of data. The results of this study show that the participants perceive published educational research as both a means of representation, as well as potential obstacle. This research has some limitations, for example, the number of participants across countries are 12 which cannot be generalised or make a representation on a single country. Again, the participants involved only English language teachers. The contexts of the participants did not include Kuwait context.

As noted above, these studies were conducted in several contexts across the globe; however, there is a lack of published educational research in Kuwait context and we believe socio-cultural context varies. Again, most of the previous studies reviewed above and others not mentioned were mostly concerned with the English language teachers alone rather than teachers in general. Furthermore, some of the studies did combine several stakeholders as their participants instead of concentrating more on teachers, who are the critical consumers of the research. Other studies as noted above suggested further studies to gain more insights across different contexts and languages such as Arabic language teachers' engagement with published educational research in Kuwait. As a result of this, the present study seeks to investigate Arabic language teachers' engagement with published educational research in Kuwait's secondary schools. This research is aimed to address the following research questions:

1. To what extent do secondary schools Arabic language teachers in Kuwait read published educational research?

2. To what extent do secondary schools Arabic language teachers in Kuwait conduct research?

3. To what extent do the institutional cultures motivate secondary schools Arabic language teachers in Kuwait to engage with educational research?

\section{Methodology}

This study was conducted in Kuwait's secondary schools across six educational regions of the country. The educational regions were: Al asemah, Hawaly, Al Farwanyah, Al jahra, Mubark Al Kabir, and Al Ahmady. Anon-experimental research design was used. The purpose was to gain insight on how teachers use published educational research. Therefore, we used a descriptive research as 'the primary purpose of descriptive research is to provide an accurate description or picture of the status or characteristics of a situation or phenomenon' (Johnson and Christensen, 2008: 377).

As noted above, this study was conducted across six educational regions of Kuwait, it used a quota sampling in selecting participants across these regions. As explained in the preceding sentence that this study used a quota sampling on the basis that in Kuwait's public secondary schools, we have six educational regions as noted above. The rationale for choosing this sample strategy was to have representation of certain characteristics of the wider population (Cohen, Manion, and Morrison, 2013: 114). We approached contacts in a number of Arabic language teachers across these six educational regions who were in a position to invite practising Arabic language teachers to complete the questionnaire. It used a quota sampling participants of 170 across these regions. The questionnaire data were analysed statistically using SPSS. 


\section{Results and Discussion}

As can be seen in appendix 1 some of the key items on our questionnaire are questions related to the concept of published educational research, Arabic language teachers' engagement with published educational research to enhance their professional development, encouragement from the stakeholders regarding the use of published educational research and available of facilities and resources to implement recommendation of the published educational research. So all the questions asked the respondents to tick appropriate answer. Below are the results of our analysis of the data.

In table 1 below, the results show that 86 per cent of the members of staff have educational qualification of Bachelor degree, while 9 per cent has Master degree and 5 per cent has $\mathrm{PhD}$ degree. This indicates that the Arabic language teachers who have lower minimum educational qualification of Bachelor degree represent 86 per cent of the participants. This might have a negative impact regarding their teaching and learning, as well as teachers' professional development on the basis that the curriculum of Bachelor's programme is not largely devoted to research rather is more of theoretical approaches. However, most of the modules of Master's and PhD programmes are addressing issues related to both theoretical, methodological and research approaches. This could have a negative impact on both the students and teachers because the teachers with lower qualification of Bachelor degree who constitute 86 per cent of the respondents might not have appropriate knowledge on how to conduct and use published educational research. However, a chi-square tests is conducted to determine whether there are significant differences among the holders of various qualifications. The chi-square statistic is 30.8571 . The $p$-value is $<.00001$. The result is significant at $\mathrm{p}<.05$. It implies that there are significant differences among the percentages of $\mathrm{PhD}, \mathrm{MA}$ and Bachelors' degree holders.

Table 1. Teachers' educational qualifications

\begin{tabular}{llll}
\hline & Qualification & $\begin{array}{l}\text { Number } \\
\text { participants }\end{array}$ & of \\
\hline $\mathbf{1}$ & PhD & 9 & 5 \\
$\mathbf{2}$ & MA & 15 & 9 \\
$\mathbf{3}$ & Bachelor & 146 & 86 \\
& Totals & $\mathbf{1 7 0}$ & $\mathbf{1 0 0}$ \\
\hline
\end{tabular}

The results in table 2 below shows years of working experiences of the participants, as can be seen from the table teachers who are in categories of working experience from 6 to above 21 years constitute 78 per cent of the total number of the participants, implying that majority of the teachers have long years of working experiences. However, the other results below show that the long years of working experience do not show any positive impact in relation to their engagement with published educational research, which could improve their teaching and learning, as well as their professional development.

Table 2. Teachers' working experience

\begin{tabular}{llll}
\hline & Working experience & $\begin{array}{l}\text { Number of } \\
\text { participants }\end{array}$ & Percentage \\
\hline $\mathbf{1}$ & $1-5$ years & 37 & 22 \\
$\mathbf{2}$ & $6-10$ & 59 & 35 \\
$\mathbf{3}$ & $11-20$ & 55 & 32 \\
$\mathbf{4}$ & 21 and above & 19 & 11 \\
& Totals & $\mathbf{1 7 0}$ & $\mathbf{1 0 0}$ \\
\hline
\end{tabular}

The results of table 3 below indicate the participants' perceptions about the concept of published educational research. The data shows that 38 per cent of the respondents view educational research as an electronic text article. Again, another 38 per cent of the respondents consider published educational research as an educational website; while 14 per cent perceive published educational research as specialist journal article; and 10 per cent views the published educational research as an educational journal article. Following this, only 10 per cent of the respondents have clearly understood what published educational research is and how it could impact on the teachers' professional development, as well as teaching and learning. This indicates that 90 per cent of the respondents do not have an overview of what published educational research is all about, because 76 per cent of the respondents view published 
educational research either any electronic text or any educational website. Again, a chi-square test is administered. The chi-square statistic is 19.2. The $p$-value is .000012 . The result is significant at $p<.05$, implying that there are significant differences between the two groups of percentages: $90 \%$ and $10 \%$. This could have a negative impact on their professional development because they do not under what published educational research is. It could be possible this misunderstanding of the concept of published educational research can be attributed to the low-level of educational qualification of the respondents. Since we argue above that the Bachelor degree programme is mostly dealing with proposition rather than research unlike the postgraduate programmes which are mostly dealing with in-depth research, methodology, as well as theoretical approaches.

The next question in the questionnaire as can be seen in appendix 1 asked the respondents whether they have been publishing educational research. Their responses show that 94 per cent of the respondents have not been publishing any educational research. The chi-square statistics is 27.9231 . The $\mathrm{p}$-value is <.00001. The result is significant at $\mathrm{p}<.05$, implying that there are significant differences between the two groups: $94 \%$ and $6 \%$. It might be possible the higher percentage of the participants who do not publish educational research could also be attributed to the low-level of educational qualification as noted above. It could also be possible that there is a lack of encouragement from the educational stakeholders regarding conducting, as well as publishing research.

Table 3. Arabic language teachers' perceptions about published educational research

\begin{tabular}{llll}
\hline & & $\begin{array}{l}\text { Number } \\
\text { participants }\end{array}$ & of \\
\hline $\mathbf{1}$ & Electronic text article & 64 & 38 \\
$\mathbf{2}$ & Educational website & 65 & 38 \\
$\mathbf{3}$ & Specialist journal article & 23 & 14 \\
$\mathbf{4}$ & Educational journal article & 18 & 10 \\
& Totals & $\mathbf{1 7 0}$ & $\mathbf{1 0 0}$ \\
\hline
\end{tabular}

The next question asks the respondents whether they are reading published educational research. The results as can be seen in table four below indicates that 88 per cent said that they are not reading published educational research; whereas only 12 per cent shows that they have been reading published educational research. The chi-square statistic is 16.0742 . The $\mathrm{p}$-value is .000061 . The result is significant at $\mathrm{p}<.05$. Again, it indicates that there are significant differences between the two groups: $88 \%$ and $12 \%$. This question prompted a series of check list questions as can be seen in table five below.

Table 4. Do you read published educational research?

\begin{tabular}{llll}
\hline & & $\begin{array}{l}\text { Number } \\
\text { participants }\end{array}$ & of \\
\hline $\mathbf{1}$ & Yes & 21 & 12 \\
$\mathbf{2}$ & No & 149 & 88 \\
& Totals & $\mathbf{1 7 0}$ & $\mathbf{1 0 0}$
\end{tabular}

The results in table five below indicate a number of reasons that Arabic language teachers' are not reading published educational research. For example, 12 per cent of the participants show that they do not have enough time to read the research. It might be possible the teachers have a lot of work load, which could not allow them to read and analyse the research and to see how relevant is to their context. It could also possible that their peers are not reading published educational research and they also feel that there is no need to read as in the case of Borg's (2009) findings. Again, 15 per cent of the respondents believe that the published educational research is not relevant to their practical teaching. In other words, the findings of research do not provide practical teaching implications. This view is in consonant with Anwaruddin and Pervin (2015) view who argue that researchers do not attend to the needs of educational practitioners. For example, they construct research questions, as well as designing research methodology without due consultation with practitioners. Again, it confirms the assertion of Vanderlinde and Van Braak (2010) who have argued there a gap between a research-based knowledge, which usually published in scientific journals and a pedagogical knowledge, which teachers use in the classroom for their day-to-day teaching. Again, it also confirms the findings of Borekkamp \& van Hout-Wolters (2007) which indicate that practitioners make little or no use of findings of published educational research on the basis that the findings of such research provide very few conclusive and practical results. It is also in consonant with findings of some scholars who argue 
that the research evidence use within the teaching profession has been very scanty (Nelson \& O'Beirne, 2014 and Levin, 2013).

The results also show that 36 per cent of the respondents' reason was lack of support from their schools. As stated above, this study is quantitative rather than a mixed-methods or qualitative which could have afforded us with more explanations and insights of the kind of supports that they have not been given. However, this reason could be explored more in the subsequent section. The last reason in the table is to do with lack of the management to acknowledge the effort of the participants who may have demonstrated commitment in reading published educational research. These respondents account for 37 per cent of the total respondents. It indicates that 73 per cent of the respondents' reasons are related to lack of support and acknowledgement from the schools, which we explore more in the subsequent section. The chi-square statistic is 4.1342 . The $p$-value is .042026 . The result is significant at $p$ $<.05$. Again, the results of the chi-square test show that there are significant differences between the two groups: $73 \%$ and $27 \%$.

Table 5. Reasons for not reading published educational research

\begin{tabular}{llll}
\hline & & $\begin{array}{l}\text { Number } \\
\text { participants }\end{array}$ & of \\
\hline $\mathbf{1}$ & No time & 21 & 12 \\
$\mathbf{2}$ & Not related to my practical teaching & 26 & 15 \\
$\mathbf{3}$ & There is a lack of support from my school & 61 & 36 \\
$\mathbf{4}$ & My management does not acknowledge teachers' effort & 62 & 37 \\
& Totals & $\mathbf{1 7 0}$ & $\mathbf{1 0 0}$ \\
\hline
\end{tabular}

The results in table 6 below show reasons that the Arabic language teachers are not engaging with published educational research. For example, 12 per cent of the respondents believe that there is a lack of facilities which could enable them to implement the findings and recommendations of the published educational research. This indicates that even if teachers want to implement the findings of a study, they are confronting with difficulties of getting appropriate facilities to implement the findings. This corroborates Borg's (2009) findings that teachers have moderate level of reading and doing research, which they attribute to the lack of time, knowledge, as well as access to material, which teachers believe as main factors that limit their ability to be engaged in research. Again, it also indicates that 35 per cent of the respondents are of the opinion that there is a lack of encouragement from the management of the schools. This also corroborates Anwaruddin and Pervin (2015) findings that 90 per cent of their respondents attribute non-engagement with published educational research on the poor attitude of the management of institutions to encourage the teachers. As noted in table 5 above on the lack of acknowledgement of teachers' effort by the management regarding reading published educational research, here we explore similar question in relation to the reasons for not engaging with published educational research. The results show that 12 per cent of the respondents are still believe that lack of the acknowledgement by the management of their schools make them reluctant to engage with published educational research. It could be possible that whether a teacher engages or not engages with published educational research such teacher will be promoted to the next level. For example, in some universities a lecturer could only be promoted if he/she publishes certain number of research in reputable journals. It might be possible when teachers engage with published educational research, the management of the institution does not consider it for promotion neither they give them any letter of commendation.

The last question in table 6 below asks whether teachers are getting support in relation to their engagement with published educational research as can be seen in the table, 41 per cent believe that teachers are not getting support. The chi-square statistic is 0.5524 . The p-value is .457327 . The result is not significant at $p<.05$ it shows that there are insignificant differences between the two groups: $41 \%$ and 59\%. Although this study is quantitative rather than qualitative, which could have afforded us with more insights of the kinds of support. It could be possible the lack of support might be in relation to financial which would assist the teachers to engage with the published educational research. It could also be possible the lack of support is to do with a provision of materials to engage with the published educational research. 
Table 6. Reasons for not engaging with published educational research

\begin{tabular}{llll}
\hline & & $\begin{array}{l}\text { Number } \\
\text { participants }\end{array}$ & of \\
\hline $\mathbf{1}$ & Lack of facilities to implement the findings & 20 & 12 \\
$\mathbf{2}$ & Lack of encouragement from the management of the school & 60 & 35 \\
$\mathbf{3}$ & Lack of acknowledgement & 20 & 12 \\
$\mathbf{4}$ & Lack of support & 70 & 41 \\
& Totals & $\mathbf{1 7 0}$ & $\mathbf{1 0 0}$ \\
\hline
\end{tabular}

\section{Implications for Teachers' Professional Development}

As the results shown various reasons that teachers do not read and engage with published educational research, which corroborate many studies conducted across the globe in relation to the relevant of published educational research to teachers' professional development. Following our findings, we strongly recommend that there should be raising of awareness of the teachers on the importance of published educational research because our results show that a significant number of respondents do not know what is published educational research. Again, the result also indicates that 86 per cent of the respondents have Bachelor degree certificate which the content of the modules of Bachelor degree is not on research-base, as such they might have low level understanding of research, as well as how to engage with it. Thus, raising of awareness of the teachers is very important. This could assist in improving their professional development.

Again, Hargreaves (1996) argues that teaching profession should become 'an evidence-based profession if educational researchers were made more accountable'. Hemsley-Brown and Sharp (2003:449) have also argued that 'this could be achieved through a coordinated approach to research', such research would focus on pedagogical implications. For Borg (2010: 410) 'teachers should be critical consumers of educational research, using it to inform their instructional decisions'. Following this, researchers should take into cognisance the important roles that teachers could play in the implementation of the findings of the research since they are the critical consumers of the findings of the research.

We also suggest the development of individual teachers' capacity-building such as teachers' research literacy. This could probably assist teachers to develop their reading and writing, as well as engaging with published educational research. Again, we advocate the development of an institutional committee which could support teachers' engagement with research. This could be possible in many ways. For example, institution could establish a research committee which would encourage, support, and acknowledge the roles of members of staff in relation to their engagement with published educational research. It could also be in a form of financial incentives or a letter of commendation for members of staff who are engaging with published educational research. This might help in developing teachers' professional development in relation to their engagement with published educational research.

\section{Conclusion}

In conclusion, as noted many scholars have argued that there is a gap between published educational research and research and practice in the field of education (Anwaruddin and Pervin, 2015; Anwaruddin, 2013; Hargreaves; Hemsley-Brown and Sharp; 2003; Ball, 2012; and Vanderlinde and Van Braak, 2010). This study also corroborates the previous findings as shown above. We recommend a number of approaches which could improve the teachers' professional development in relation to their engagement with published educational research. For example, raising of awareness of teachers of the importance of published educational research on their professional development. Researchers should take into cognisance of teachers' roles in implementing findings of their research, through seeking their opinions in relation to the teaching implications of the findings. We also advocate organisational cultures which could support teachers' engagement with published educational research.

However, this study has some limitations, one of its limitations is to do with inability to explore and gain more insights from the participants through conducting interviews which could have afforded us with more explanations of their lack of engagement with published educational research. Again, this study is relatively involved a few number of participants, which we could not make a general conclusion regarding Arabic language teachers' engagement with published educational research in Kuwait's secondary schools. 
We recommend further study which will integrate both quantitative and qualitative approaches, as well as involving more participants across the country in order to get a broader picture of Arabic language teachers' engagement with published educational research.

\section{Acknowledgement}

We would like to thank all the participants of this study for their great contributions in relation to the successful conduct of this research.

\section{References}

Anwaruddin, S.M. (2016). Language teachers' responses to educational research: addressing the 'crisis' of representation. International Journal of Research \& Method in Education, 39(3), 314-328. https://doi.org/10.1080/1743727X.2016.1166485

Anwaruddin, S.M. and Pervin, N. (2015). English-language teachers' engagement with research: findings from Bangladesh. Professional Development in Education, 41(1), 21-39. https://doi.org/10.1080/19415257.2013.861860

Ball, A.F. (2012). To know is not enough knowledge, power, and the zone of generativity. Educational Researcher, 41(8), 283-293. https://doi.org/10.3102/0013189X12465334

Bates, R. (2002). The impact of educational research: Alternative methodologies and conclusions*. Research Papers in Education Policy and Practice, 17(4), 403-408. https://doi.org/10.1080/0267152022000031379

Biesta, G. (2007). Why "what works" won't work: Evidence - based practice and the democratic deficit in educational research. Educational theory, 57(1), 1-22. https://doi.org/10.1111/j.1741-5446.2006.00241.x

Biesta, G.J. (2010). Why 'what works' still won't work: From evidence-based education to value-based education. Studies in Philosophy and Education, 29(5), 491-503. https://doi.org/10.1007/s11217-010-9191-x

Bolam, R. (1994). The impact of research on policy and practice in continuing professional development. Journal of In-Service Education, 20(1), 35-46. https://doi.org/10.1080/0305763940200104

Borg, S. (2009). English Language Teachers' Conceptions of Research. Applied Linguistics, 30(3), 358-388. https://doi.org/10.1093/applin/amp007

Borg, S. (2010). Language teacher research engagement. Language Teaching, 43(4), 391-429. https://doi.org/10.1093/applin/amp007

Broekkamp, H. and van Hout-Wolters, B. (2007). The gap between educational research and practice: A literature review, symposium, and questionnaire. Educational Research and Evaluation, 13(3), 203-220. https://doi.org/10.1080/13803610701626127

Cain, T. (2015). Teachers' engagement with published research: addressing the knowledge problem. The Curriculum Journal, 26(3), 488-509. https://doi.org/10.1080/09585176.2015.1020820

Cohen, L. et al. (2013). Research methods in education. London: Routledge.

Furlong, J. 2004. BERA at 30. Have we come of age? British Educational Research Journal, 33(3), 343-358. https://doi.org/10.1080/01411920410001689670

Hammersley, M. (1997). Educational research and teaching: a response to David Hargreaves' TTA lecture. British Educational Research Journal, 23(2), 141-161. https://doi.org/10.1080/0141192970230203

Hargreaves, A. and Fullan, M.G. (1992). Introduction. New York Teachers College Press.

Hargreaves, D.H. (1996). Teaching as a research-based profession: possibilities and prospects. Teacher Training Agency London.

Hemsley-Brown, J. and Sharp, C. (2003). The Use of Research to Improve Professional Practice: a systematic review of the literature. Oxford Review of Education, 29(4), 449-471. https://doi.org/10.1080/0305498032000153025

Johnson, B. and Christensen, L. (2008). Educational research: Quantitative, qualitative, and mixed approaches. Thousand Oaks, Calif, Sage.

Kennedy, M.M. (1997). The connection between research and practice. Educational researcher, 26(7), 4-12. https://doi.org/10.3102/0013189X026007004 
Levin, B. (2013). To know is not enough: research knowledge and its use. Review of education, 1(1), 2-31. https://doi.org/10.1002/rev3.3001

McIntyre, D. (2005). Bridging the gap between research and practice. Cambridge Journal of Education, 35(3), 357-382. https://doi.org/10.1080/03057640500319065

Monette, D.R. et al. (2013). Applied social research: A tool for the human services. Cengage Learning.

Morrison, K. 2001. Randomised controlled trials for evidence-based education: some problems in judging'what works'. Evaluation \& Research in Education, 15(2), 69-83. https://doi.org/10.1080/09500790108666984

Nutley, S. et al. (2003). From knowing to doing a framework for understanding the evidence-into-practice agenda. Evaluation, 9(2), 125-148. https://doi.org/10.1177/1356389003009002002

Sharples, J. (2013). Evidence for the Frontline. London: Alliance for Useful Evidence.

Slavin, R.E. (2002). Evidence-based education policies: Transforming educational practice and research. Educational researcher, 31(7), 15-21. https://doi.org/10.3102/0013189X031007015

Tavakoli, P. and Howard, M.J. (2012). Teaching English to speakers of other languages teachers' views on the relationship between research and practice. European journal of teacher education, 35(2), 229-242. https://doi.org/10.1080/02619768.2011.643398

Torgerson, C.J. and Torgerson, D.J. (2001). The need for randomised controlled trials in educational research. British Journal of Educational Studies, 49(3), 316-328. https://doi.org/10.1111/1467-8527.t01-1-00178

Vanderlinde, R. and van Braak, J. 2010. The gap between educational research and practice: Views of teachers, school leaders, intermediaries and researchers. British Educational Research Journal, 36(2), pp.299-316. https://doi.org/10.1080/01411920902919257

Wikeley, F. 1998. Dissemination of research as a tool for school improvement? School Leadership \& Management, 18(1), 59-73. https://doi.org/10.1080/13632439869772 


\section{Appendix I}

\section{Questionnaire on Arabic language teachers' engagement with published educational research in Kuwait's secondary schools}

You are invited to take part on a research entitled: Arabic language teachers' engagement with published educational research in Kuwait's secondary school. We assure you that your identity will not appear in any documents relevant to this research. This questionnaire is aimed to get more insights on the Arabic language teachers' engagement with published educational research is not meant to evaluate your performance in relation to teachers' professional development. Pleas tick the appropriate answer.

1. Sex
a. Male
b. Female

2. Could you tick the category of working experience you belong to:
a. $0-5$
b. $6-10$
c. $11-20$
d. From 20 to above

3. Could you tick the appropriate qualification you possess?
a. Masters Degree
b. Bachelor Degree

4. How do you perceive published educational research?
a. Electronic text article
b. Educational website
c. Specialist journal article
d. Educational journal article

5. Do you read published educational research?
a. Yes
b. No

6. If you are not reading published educational research, what are your reasons for that?
a. No time
b. Not related to my practical teaching
c. There is a lack of support from my school
d. Lack of acknowledgement of the management for teachers' effort.

7. Do you engage with published educational research to improve your teaching practice?
a. Yes
b. No

8. If not, what are your reasons?

a. Lack of facilities to implement the findings

b. Lack of encouragement from the management of the school

c. Lack of acknowledgement

d. Lack of financial support

Many thanks for having time to fill in this questionnaire. I assure you that your identity will not appear in any materials related to this study. 